\title{
Capacity legislation for Ireland: filling the legislative gaps
}

\author{
Peter Leonard, Martin McLaughlin
}

Ir J Psych Med 2009; 26(4): 165-168

In a legal context the term 'capacity' is used to refer to a person's ability to make a decision with legal consequences. Capacity is a threshold requirement for persons to have the power to make enforceable decisions for themselves and so is the core issue in balancing the persons right to autonomy in decision making with a professional and ethical duty to protect them from harm.

The publication of the Mental Capacity and Guardianship Bill $2008^{1}$ encourages hope that long awaited capacity legislation will finally be delivered for the Republic of Ireland.

The 2008 Bill has been expanded by a Scheme of Mental Capacity Bill $2008^{2}$ which was published in September 2008. The Bill has adopted the template set out by the Law Reform Commission ${ }^{3}$ and seek to provide a substitute decision making process for those without capacity through the establishment of a Guardianship Board, an Office of the Public Guardian and appointment of Personal Guardians to assist with decision making for adults who do not have capacity.

In Part 2 this Bill upholds the presumption of an individuals capacity unless there is evidence to the contrary, defines capacity and through this definition implies that the functional test of capacity is the favoured approach.

The lack of a clear definition of incapacity which can be measured contrasts with recent legislation in England and Scotland and makes the practical application of this legislation difficult.

Part 2 (8) gives guidance in relation to provision of care for those whose capacity is in doubt. This guidance entails applying the core principles of the Bill (Part1 (4)) which are: necessity, use of least restrictive option, respect for a persons past and present wishes, account to be taken of the views of relatives/carers, respect for the (un-enumerated constitutional) rights to dignity, bodily integrity, privacy and autonomy. The inclusion of such core principles gives a sound theoretical underpinning to the Bill but sadly leaves those on the ground with little practical guidance as to how they should deal with the day to day care of those who may lack decision making capacity.

The Bill empowers the Guardianship Board ( Part 3(16)) to make "Guardianship orders" and "Intervention orders" in cases where persons lack capacity. However decisions

*Peter Leonard, Consultant Psychiatrist, St Joseph's Intellectual Disability Service, St Ita's Hospital, Portrane, Donabate, Co. Dublin, Martin McLaughlin, Clinical Director, The Daughters of Charity, St Vincent's Centre, Navan Rd, Dublin 7 and Consultant Psychiatrist, St Patrick's Hospital, Dublin 2, Ireland.

*Correspondence

SUBMITTED: APRIL 29, 2008. ACCEPTED: SEPTEMBER 5, 2009. regarding organ donation, withdrawal of life sustaining treatment and authorising of non therapeutic sterilisation will rest with the High Court. In effect this process would also result in the abolition of Wardship ${ }^{4}$ system and in many respects replaces it with a similar system.

\section{The existing clinical dilemma}

In clinical practice the pivotal importance of decision making capacity relates to its place as an essential ingredient for valid consent

The three ingredients to valid consent are as follows:

- Consent is given voluntarily ("full, free and unfettered")

- Consent is given by a person with legal capacity to consent (ie. an adult of sound mind)

- Consent is informed or in other words the doctor has discharged his duty to provide all information relevant to the decision.

In the absence of enacted Capacity legislation a number of unsatisfactory approaches have traditionally been employed in Ireland when a patient does not have decision making capacity.

\section{Consent from the next of kin}

Once a person reaches the age of majority a parent or guardian cannot consent to or refuse treatment on their behalf. ${ }^{5}$ This legal situation is contrasted with the reality in clinical practice where relatives / next of kin /carers are commonly asked to consent on behalf of a person without capacity.

In guiding best practice in the absence of legal protections, the Irish Medical Council advises ${ }^{6}$ that in the case of a patient who lacks capacity a "wide ranging consultation" should take place with "parents/guardians and appropriate carers" and " a second opinion should be considered".

\section{The doctrine of necessity}

When faced with the dilemma of treating a patient who cannot give consent many doctors will act according to the "doctrine of necessity". This principle may provide legal defence for treating someone without valid consent where there is "necessity to act"."

The doctrine of necessity was established in Ireland in the case of Holmes $v$ Heatley. ${ }^{8}$

In this case a boy was given an anaesthetic in an emergency situation without consent and Maguire $J$ found that medical treatment without consent in an emergency is lawful and a defence to a charge of battery.

The key source of precedent in relation to the doctrine of necessity in English case law is the case of In Re F (Mental Patient: Sterilisation). ${ }^{9}$ This case potentially broadened the application of necessity beyond the emergency situation. 
In considering this case Lord Goff found that the principle of necessity has two components. These are necessity to act when it is not practicable to communicate with the assisted person, and action in keeping with what a reasonable person would do in the best interests of the assisted person. Lord Goff also stated that the principle was one of "necessity not emergency", thus broadening the application of the principle to routine treatment procedures.

It was also stated as guidance that doctors should act on the basis of good professional practice, consult relatives and others interested in the care of the person.

Such a broad remit for the doctrine of necessity has not been established in Irish case law.

In fact in the case of In Re a Ward of Court (No 2), ${ }^{10}$ Denham J stated that one of the few exceptions to the requirement for informed consent is in the case of a medical emergency situation where the patient cannot communicate his or her wishes.

Consistent with the latter, the current Medical Council Guidelines ${ }^{11}$ are also in keeping with the restriction of the doctrine of necessity to emergency situations.

The principle of "best interest" was also referred to in Re a Ward of Court (No 2). ${ }^{12}$

Lynch J underlined the importance of respecting the persons prior wishes (if they can be determined) and described the position of the Court in determining best interests as that of a "prudent, good and loving parent".

\section{Wards of Court}

Wardship currently provides the main legitimate avenue for substitute decision making in Ireland. When an adult has been made a Ward of Court the President of the High Court has the authority to make healthcare decisions on his/ her behalf. In cases of routine and non-controversial procedures the Registrar of the Wards of Court may then delegate decision making authority to the person's next of kin. ${ }^{13}$ The ultimate disadvantage of Wardship is that it is unwieldy, and does not allow a speedy response to more routine day to day clinical situations .

\section{The 'Bournewood Gap'}

Many people who lack capacity are passively acquiescent with treatment. To some extent it is for this reason that there has been little controversy regarding the stark lack of Capacity Legislation in Ireland. The principal case which dealt with this issue in the UK is that of Bournewood. ${ }^{14}$

This case related to the legal controversy surrounding the admission and treatment of a man who lacked capacity to give consent to treatment but was acquiescent.

Initially the House of Lords ruled that the person at the centre of the case did not require to be admitted involuntarily under Mental Health Law ${ }^{15}$ but a subsequent 2004 ruling by the European Court of Human Rights on the Bournewood case found that H.L. was deprived of his liberty contrary to article 5(1) of the European Convention on Human Rights because his admission was not "in accordance with a procedure prescribed by law" and was contrary to article 5(4) because he was unable "to take proceedings by which the lawfulness of his detention shall be decided speedily by a court".

The enactment of Irish Capacity Legislation may prevent the occurrence of an Irish Bournewood case by providing a solution for such situations in which recourse to the Mental Health Act 2001 is inappropriate as the person commonly will not meet the legal criteria for Mental Disorder as defined in the Mental Health Act 2001.

\section{Assessing capacity in practice}

Several approaches have been described in the literature for determining decision making capacity. Arscott ${ }^{16}$ has summarised three approaches:

- The diagnostic approach (similar to the status approach)

- The outcome approach

- The functional approach (now the most favoured).

The diagnostic or status approach is out of favour nowadays as it essentially relates capacity to membership of a diagnostic group (Intellectual disability, dementia, mental illness). This approach is far too blunt to be useful and does not assess capacity in context. The outcome approach measures the individual's ability to make decisions on the basis of the consequences of those decision making choices. In essence this means that if the person's choice does not reflect those views widely held and rejects conventional wisdom ${ }^{17}$ then he is deemed to lack capacity. This approach has largely been rejected as it errs on the side of protection rather than enabling autonomy and choice.

The Functional approach has been widely adopted both in Ireland and the UK. In its discussion document Vulnerable Adults and the Law: Capacity ${ }^{18}$ the Irish Law Reform Commission has endorsed this approach and this is now reflected in The Mental Capacity and Guardianship Bill 2008.

This approach involves an assessment in relation to a specific choice at a specific point in time. The persons functional abilities are assessed in relation to the skills required for decision making and a judgement is made by the assessor as to whether or not the persons abilities meet the demands of the decision in question.

The functional abilities which are most commonly cited as relevant to decision making have been outlined by Wong et $a /^{19}$ and are as follows:

- Understanding information relevant to the treatment

- Retaining relevant information

- Manipulating information rationally

- Appreciating the situation and its likely consequences

- Communicating a choice.

Arscott ${ }^{20}$ has described the advantages of the functional approach as being: greater reliability, acknowledgement of fluctuating nature of capacity and requirement for periodic assessment and the possibility of improving an individuals relevant functional abilities. The disadvantages are that the amount of information required to be understood is not easily determined, and borderline cases are hard to assess.

One significant advantage of this approach is that it has been operationalised and can be measured with reliability using instruments such as the MacArthur Competence Assessment Tool - Treatment. ${ }^{21}$ This allows one the advantage of a validated instrument and a clearly defined process for functional assessment of decision making capacity.

One can reasonably anticipate that many people with an Intellectual Disability will come under the remit of future capacity legislation. The currently available comperence assessment tools have not been developed for this population 
and so there is an urgent need for the development of appropriate instruments which rely more on visual material rather than text.

\section{Lessons to be learned from UK Legislation \\ England}

In recent years both Scotland and England have enacted Capacity Legislation and Codes of Practice. The most recent of these developments is the English Mental Capacity Act $2005^{22}$ and Code of Practice. ${ }^{23}$ The provisions and principles of the English Act are in many respects similar to the Irish Bill. However, the English Act has included a definition of incapacity which includes mental disorder as a necessary ingredient:

"A person lacks capacity in relation to a matter if at the material time he is unable to make a decision for himself in relation to the matter because of an impairment of or a disturbance in the functioning of mind or brain. It does not matter whether the impairment or disturbance is permanent or temporary".

The requirement for the presence of mental disorder is omitted from the Irish Bill although it is very necessary and described by Kennedy as an essential ingredient of capacity legislation. ${ }^{24}$ This omission raises the risk that conditions such as personality disorders and addictions which are sensibly excluded from the application of Irish Mental Health Legislation may come under the remit of Capacity Law.

The operation of the English Act is based on the principle that capacity should be assessed by the worker who is normally directly involved with the person whose capacity is in doubt. Depending on the approach taken in Ireland, this issue may involve the redefining of traditional professional roles and this will require discussion and debate within and without the medical profession as to who is best qualified to assess capacity. It is best that a collaborative approach should be applied which involves the relevant professionals and carers.

In the current economic climate it is to be anticipated the least expensive option is most attractive to government but it is essential that valid assessments are undertaken by appropriately trained persons.

The Irish Office of the Public Guardian will have primary responsibility for producing a Code of Practice ${ }^{25}$ similar to that which has been produced in England. This will ultimately provide essential procedural guidance for day to day practice. In addition an Irish Working Group ${ }^{26}$ will be tasked with defining codes of practice in relation to "assessment of capacity" and "circumstances in which urgent treatment may be carried out without the consent of an adult patient".

\section{Scotland}

The recent Scottish Capacity Act $^{27}$ includes a definition of incapacity which can be applied in practice. 'Incapable' means incapable of:
(a) Acting; or
(b) Making decisions; or
(c) Communicating decisions; or
(d) Understanding decisions; or

(e) Retaining the memory of decisions.

When compared with this the Irish Bill is much more flimsy and simply defines capacity (rather than incapacity) as:
"The ability to understand the nature and consequences of a decision in the context of available choices at the time the decision is made".

This lack of a clear definition of incapacity makes it extremely difficult to measure incapacity in practice.

It is worth noting that Scotland also explicitly incorporated the concept of impaired capacity ("Significantly impaired decision making ability") as one ingredient of the test for involuntary admission in its Mental Health (Care and Treatment) (Scotland) Act 2003.

Experience of legislative change in Scotland has recently been reported by McCullock. ${ }^{28}$

The majority of consultant psychiatrists surveyed were confident in assessment of capacity but reported that despite attendance at induction and good awareness of the Code of Practice most of their skills were self taught. Psychiatrists also reported that disciplines outside of Psychiatry can demonstrate a poor knowledge of the Act and relatives are occasionally still being asked to sign consent forms. Feedback also suggested that the resource implications of capacity legislation had been overlooked in Scotland at the planning stage.

\section{Northern Ireland}

The Northern Irish Bamford Review ${ }^{29}$ was published in 2007 and sets out a radical framework for future legislation in the North of Ireland, stating that there should be a single framework for the reform of Mental Health Legislation and the introduction of Capacity Legislation. It sets out that this can be achieved through the framing of provisions for all those who require substitute decision making including mental health, physical health, welfare or financial needs.

This would essentially mean that a test of decision making capacity will be central to all issues involving substitute decision making including involuntary hospital admission for treatment of mental disorder.

Such a wholesale reliance on capacity testing as the single issue in determining justification for involuntary hospital admission has been the subject of intense debate. The champions of this approach tend to come from a purely ethical standpoint $\mathrm{t}^{30}$ while those who oppose it are grounded in clinical practice. ${ }^{31}$ This document raises the possibility that in future all mental health legislation may essentially be capacity legislation and the statutory roles which have been uniquely vested in doctors may be vested in other professions also.

\section{Conclusion}

The publication of the Mental Capacity and Guardianship Bill 2008 has provided a focus of attention on the desperate need for Capacity Legislation for Ireland. In the health care setting well drafted legislation could provide appropriate protection of the Human Rights of vulnerable adults and welcome protection with legitimate authority for doctors who strive to provide appropriate treatment for patients who do not have the capacity to give consent.

The absence of a diagnostic component to the definition of capacity contained in the Bill could broaden the application of this legislation beyond persons with disorders of the brain or mind. This could pose significant practical difficulties. The lack of a clear, well drafted definition of incapacity makes it unclear how incapacity can actually be clinically measured in 
accordance with this statute.

The movement towards a functional capacity test is welcome but also raises issues regarding who is trained and qualified to assess capacity.

The future success of enacted Capacity Legislation will rely on a sensible and well developed Code of Practice and an extensive educational programme.

There is a need for development of validated tools to help those on the ground to carry out assessment of capacity. This applies in particular to the assessment of persons with an Intellectual Disability.

Given the significant numbers of persons who lack decision making capacity it is hoped that a sensible system can be developed which protects human rights on the basis of collaboration, and where necessary conciliation, rather than creating a mire of costly, time-consuming legal procedure.

Finally, the resource implications of Capacity Legislation must be considered from the outset. Given the current state of local and international economic turmoil, financial considerations will pose the greatest obstacle to the timely delivery of Irish Capacity Legislation.

\section{Declaration of Interest: None}

\section{References}

1. Mental Capacity and Guardianship Bill 2008.

2. Scheme of Mental Capacity Bill 2008.
3. The Law Reform Commission (2005) Vuinerable Adults and the law : Capacity. 4. Lunacy Regulations (Ireland) Act 1871

5. Madden. Medicine ethics and the Law. 2002 Butterworths.

6. Irish Medical Council. A Guide to Ethical Conduct and Behaviour.2004. 6th Edn

7. The Law Reform Commission. Consultation paper on law and the elderly LRC CP 23-2003.

8. Holmes v Heatley (1937) 3 IR Jur Reports 74.

9. In Re F (Mental Patient: Sterilisation) [1990] 2AC

10. In Re a Ward of Court ( No 2) [1996] 2 IR 79

11. Irish Medical Council. A Guide to Ethical Conduct and Behaviour.2004. 6th Edn.

12. In Re a Ward of Court ( No 2) [1996] 2 IR 79

13. O'Neill. Wards of Court in Ireland. 2004. First Law.

14. R v Bournewood Community and Mental Health NHS Trust, ex p L [1998] 3 All

15. R v Bournewood [1999] 1 Appeal Cases 458.

16. Arscott K., Assessing the capacity of people with learning disabilities to make decisions about treatment. Tizard Learning Disability Review, 2, 17-30.

17. The Law Reform Commission (2005) Vulnerable Adults and the law : Capacity. 2.11.

18. The Law Reform Commission (2005) Vulnerable Adults and the law: Capacity.

19. Wong JG, Clare ICH., Gunn MJ, Holland AJ. Capacity to make healthcare decisions : its importance in clinical practice. Psychological Medicine. 1999; 29: 437-446

20. Arscott K., Assessing the capacity of people with learning disabilities to make decisions about treatment. Tizard Learning Disability Review, 2: 17-30.

21. Appelbaum PS, Grisso T. The MacArthur Competence Assessment Tool- Treatment. Oxford University Press. 1998

22. Mental Capacity Act 2005. HM Stationary Office.

23. Mental Capacity Act Code of Practice 2005. Department of Constitutional Affairs. 24. Kennedy H. A General theory of Mental Disorder and Consolidated Mental Disability Legislation: Commentary on the Mental Capacity and Guardianship Bill 2008. Medicolegal Journal of Ireland 2008;14 (2): 51-58.

25. Adults with Incapacity (Scotland) Act (http://www.opsi.gov.uk/legislation/scotland/ acts2000/asp_20000004_en_1)

26. Mental Capacity and Guardianship Bill 2008 Part 5, Sec 27(1).

27. Mental Capacity and Guardianship Bill 2008 Part 5 Sec 27(3).

28. McCullock J. (In)capacity legislation in practice. Psychiatric Bulletin (2009) 33 20-22.

29. The Bamford Review of Mental Health and Learning Disability (Northern Ireland) 2007.

30. Doyal J, Sheather J. Mental Health Legislation should respect decision rnaking capacity. BMJ 2005; 331: 1467-1469.

31. Chiswick D. Test of capacity has little practical benefit BMJ 2005; 331: 14691470. 


\section{GSeroquel}

Acute Mania

and

Major

Depressive

Episodes

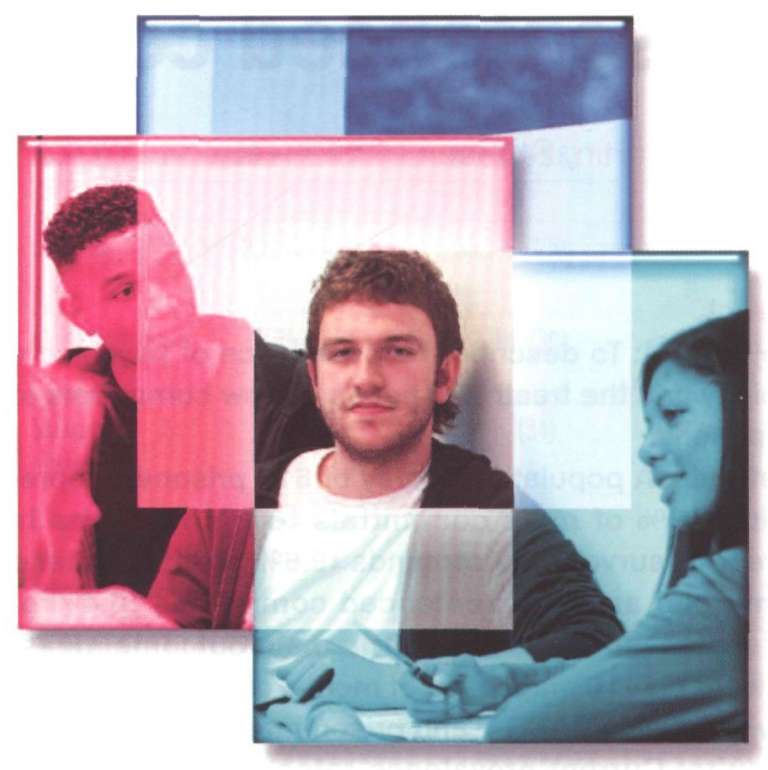

\section{in Bipolar Disorder}

\section{QS Seroquel XR \\ - DAY 4 in Bipolar Mania \\ - DAY 7 in Bipolar Depression}

Rapid symptom improvement as early as:

Seroquel $X^{T M}$ Abridged prescribing information

(For full details see summary of product characteristics). Presentations:

schizophrenic patients who have been maintained on Seroquel XR. Treatment of tholar disorder, whose manic or depressive episode has responded to que

Schizophrenia and moderate to severe manic episodes in bipolar disorder: T

however if clinically justified the dose may be increased to $800 \mathrm{mg}$ daily. The do

adjustment is necessary. Ireatment of oepressive episooes in oipolar oisord
clinical trials, no additional benefit was seen in the $600 \mathrm{mg}$ group comoared
of

can be increased in increments of $50 \mathrm{mg} /$ day to an effective dose. Efficacy \&

required. Hepatic Impairment: Use with caution. Patients should be started on

$$
\text { Depression in bipolar disorder is associated with an increased risk of suicidal th }
$$

cinical experience that the risk of suicide may increase in the early stages of recovery. In clinical studies of patients with major depressive episodes in bipolar disorder an increased

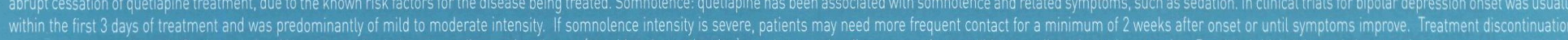

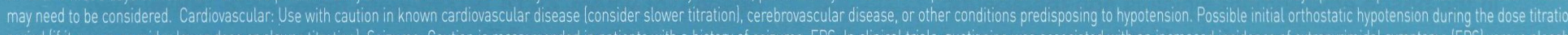

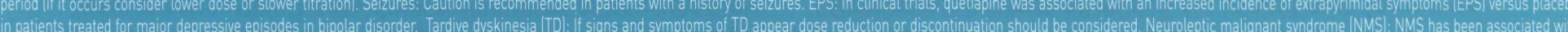

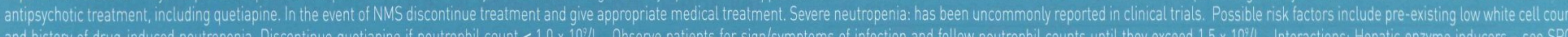
and history of drug-induced neutropenia. Discontinue quetiapine if neutroph Hyperglycaemia: Hyperglycaemia or exacerbation of pre-existing diabetes has . 